\title{
Correction to: Rarefied gas flow into vacuum through a channel with sudden contraction or expansion
}

\section{O. Sazhin ${ }^{1}$}

Published online: 1 February 2021

○) Springer-Verlag GmbH Germany, part of Springer Nature 2021

Correction to: Microfluidics and Nanofluidics (2020) 24:76 https://doi.org/10.1007/s10404-020-02384-w

In Fig. 3 the top left image is incorrect. A correct variant of the figure is given below.

Publisher's Note Springer Nature remains neutral with regard to jurisdictional claims in published maps and institutional affiliations.

The original article can be found online at https://doi.org/10.1007/ s10404-020-02384-w.

$\triangle$ O. Sazhin

oleg.sazhin@urfu.ru

1 Ural Federal University, Lenin av. 51, Yekaterinburg 620000, Russia 


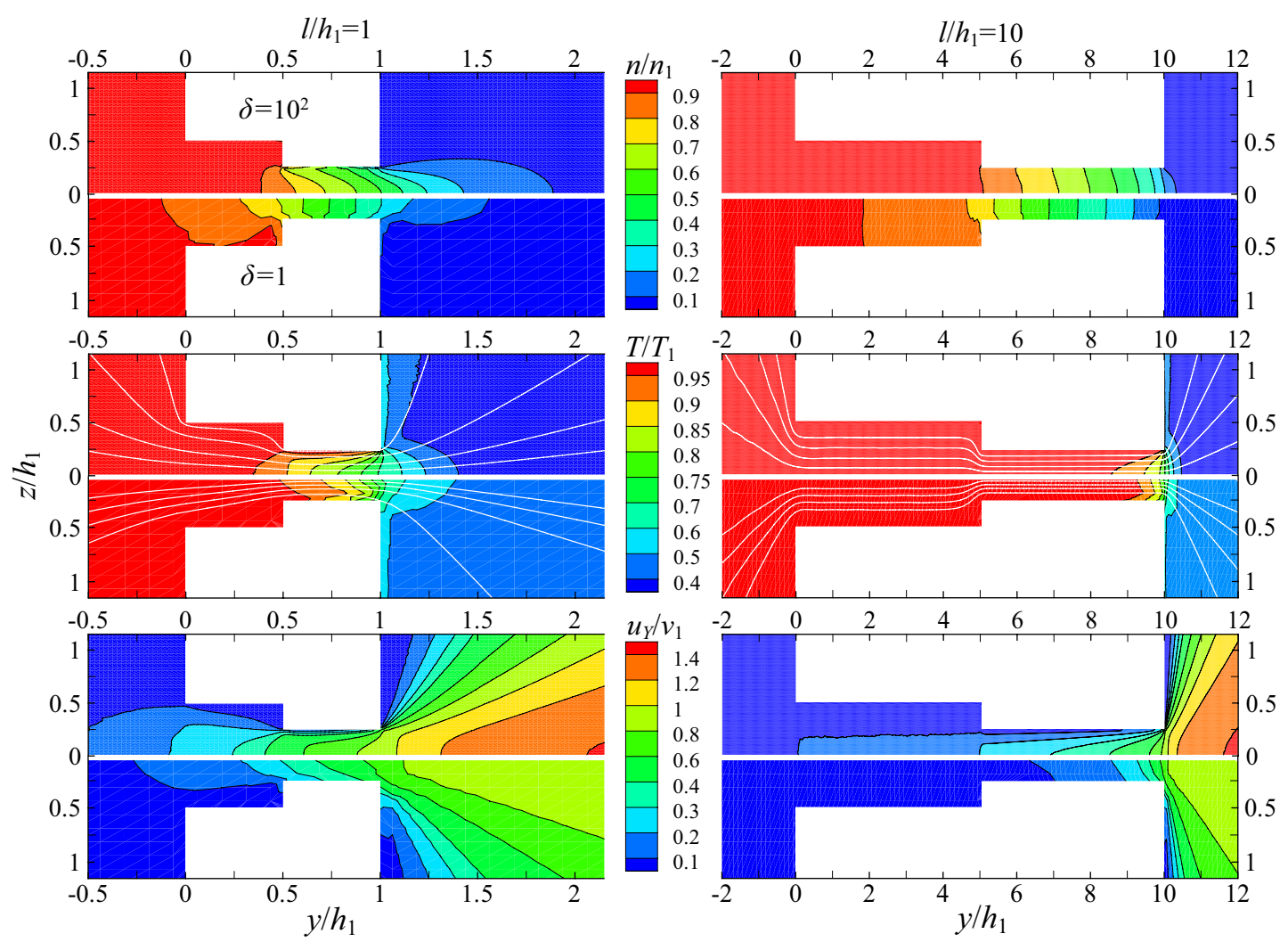

Fig. 3 Dimensionless density $n / n_{1}$, temperature $T / T_{1}$, and longitudinal bulk velocity $u_{y} / v_{1}$ in the $y z$-plane both inside and outside the channel $\left(l / h_{1}\right.$ $=1$ and 10) with sudden contraction $\left(h_{2} / h_{1}=0.5\right)$ at rarefaction $\delta=1$ and $10^{2}$. Images of temperature are also show gas streamlines 